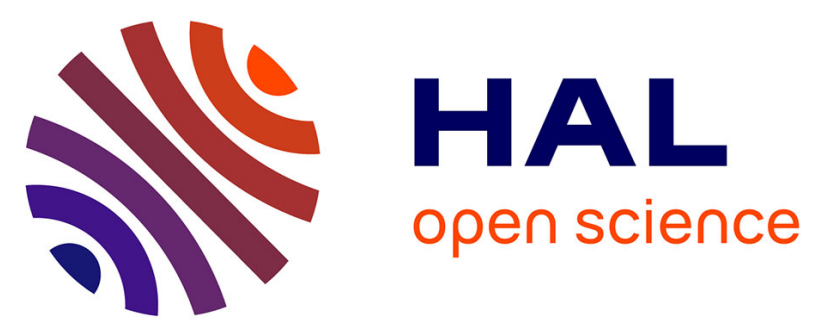

\title{
Preventive effect of bariatric surgery on type 2 diabetes onset in morbidly obese inpatients: a national French survey between 2008 and 2016 on 328,509 morbidly obese patients
}

Laurent Bailly, Luigi Schiavo, Lionel Sebastianelli, Roxane Fabre, Adeline

Morisot, Christian Pradier, Antonio Iannelli

\section{To cite this version:}

Laurent Bailly, Luigi Schiavo, Lionel Sebastianelli, Roxane Fabre, Adeline Morisot, et al.. Preventive effect of bariatric surgery on type 2 diabetes onset in morbidly obese inpatients: a national French survey between 2008 and 2016 on 328,509 morbidly obese patients. Surgery for Obesity and Related Diseases, 2019, 15, pp.478 - 487. 10.1016/j.soard.2018.12.028 . hal-03485979

\author{
HAL Id: hal-03485979 \\ https://hal.science/hal-03485979
}

Submitted on 20 Dec 2021

HAL is a multi-disciplinary open access archive for the deposit and dissemination of scientific research documents, whether they are published or not. The documents may come from teaching and research institutions in France or abroad, or from public or private research centers.
L'archive ouverte pluridisciplinaire HAL, est destinée au dépôt et à la diffusion de documents scientifiques de niveau recherche, publiés ou non, émanant des établissements d'enseignement et de recherche français ou étrangers, des laboratoires publics ou privés.

\section{(ㄷ)(1) $\$$}

Distributed under a Creative Commons Attribution - NonCommerciall 4.0 International 
Version of Record: https://www.sciencedirect.com/science/article/pii/S1550728918312450

Manuscript_bd2d2f176ca4409e2ca2106b46e3484b

\section{TITLE OF THE ARTICLE}

Preventive effect of bariatric surgery on type 2 diabetes onset in morbidly obese inpatients: a national French survey between 2008 and 2016 on 328509 morbidly obese.

MANUSCRIPT TYPE: Original Study

\section{AUTHORS}

Laurent Bailly ${ }^{1}, \mathrm{MD}, \mathrm{PhD}$, Luigi Schiavo ${ }^{2}, \mathrm{PhD}$, Anne-Sophie Schneck ${ }^{3}, \mathrm{MD}, \mathrm{PhD}$, Lionel Sebastianelli ${ }^{4}$, MD, Roxane Fabre ${ }^{1,5}, \mathrm{PhD}$, Adeline Morisot ${ }^{1}, \mathrm{PhD}$, Christian Pradier $^{1}, \mathrm{MD}, \mathrm{PhD}$, Antonio Iannelli ${ }^{5,6,7^{*}}$, MD, $\mathrm{PhD}$

\section{DEPARTMENTAL AND INSITUTIONAL AFFILIATIONS}

${ }^{1}$ Département de Santé Publique, Centre Hospitalier Universitaire de Nice (Public Health Department University Hospital of Nice), F-06202, Nice, France. Université Côte d'Azur, LAMHESS, Nice, France; ${ }^{2}$ IX Division of General Surgery, Vascular Surgery, and Applied Biotechnology, Naples University Polyclinic, Naples, Italy; ${ }^{3}$ Centre Hospitalier Universitaire de Guadeloupe, General and Digestive Surgery Unit, Pointe à Pitre, Guadeloupe, France; ${ }^{4}$ Digestive Unit, Archet 2 Hospital, University Hospital of Nice, F-06202, Nice, France; ${ }^{5}$ EA Cobtek, University of Nice Sophia-Antipolis, Nice, France; ${ }^{6}$ Inserm, U1065, Team 8 "Hepatic complications of obesity", F-06204, Nice, France; ${ }^{7}$ University of Nice Sophia-Antipolis, F $\neg 06107$, Nice, France

\section{E-MAIL ADDRESS OF EACH CONTRIBUTING AUTHOR}

Laurant Bailly, bailly.ı@chu-nice.fr

Luigi Schiavo, luigi.schiavo@unicampania.it

Anne-Sophie Schneck, escargot@yahoo.com

Lionel Sebastianelli, sebastianelli.l@chu-nice.fr

Roxane Fabre, fabre.r@chu-nice.fr

Adeline Morisot, morisot.a@chu-nice.fr

Christian Pradier,pradier.c@chu-nice.fr

Antonio Iannelli, iannelli.a@chu-nice.fr - **Corresponding Author

SHORTNED TITLE: Diabetes prevention and bariatric surgery

\section{Author Contributions}

Laurent Bailly, Luigi Schiavo, and Antonio Iannelli contributed to data conception, design, interpretation and the manuscript drafting. Ann-Sophie Schneck, Lionel Sebastianelli, Annalise Moriset, Roxane Fabre, and Christian Pradier contributed to data acquisition, statistical analysis, tables and figure preparation. 


\section{Abstract}

Background: The association between bariatric surgery (BS) and the prevention of type 2 diabetes (T2D) and its complications in patients with obesity has been rarely addressed in large nationwide database studies.

5 Objective: To estimate the preventive effect of $\mathrm{BS}$ against $\mathrm{T} 2 \mathrm{D}$ and its vascular complications in patients with obesity without comorbidity at baseline.

Setting: All French public and private hospitals

Methods: Data were extracted from the French National Health Service database between 2008 and 2016. All patients with obesity aged 18 to 60 years old, free of T2D and major comorbidities, and with at least one year of follow-up were analyzed. Patients who had undergone gastric bypass (GB), sleeve gastrectomy (SG), or adjustable gastric banding (AGB) were included in the BS group and patients with obesity with no history of BS were considered as controls.

Results: Of the 328,509 patients with obesity included, 102,627 had BS. Between 2009 and

$152016,9.7 \%(31,946$ of 328,509$)$ of patients had a diagnosis of T2D associated with morbid obesity, $13.2 \%$ of the control group versus $2.0 \%$ of the BS group $(\mathrm{p}<0.001)$. BS was associated with favorable 8-year T2D event-free survival estimates of $92.3 \%$ in the BS group against $58.2 \%$ in the control group. The hazard ratio for the diagnosis of T2D was 0.18 (95\% CI, 0.17 to 0.19 ) for the BS group versus controls, after adjustment on age, gender, BMI, and baseline differences. A significant difference was found between the type of bariatric procedure $(\mathrm{p}<0.001)$ with more T2D after AGB $(4.5 \%)$ than after GB $(1.2 \%)$ or SG $(0.9 \%)$. T2D complications were more common in controls $(\mathrm{p}<0.001)$ with multiple T2D complications occurring in $1 \%$ of patients in the control group and $0.1 \%$ in the BS group $(\mathrm{p}<0.001)$. GB and SG were more effective than AGB. 
25 Conclusions: This nationwide study shows that BS reduces the new onset of T2D in patients with obesity by $82 \%$. SG and GB give comparable results and both are more effective than AGB.

Keywords: Bariatric surgery; Type 2 diabetes; Adjustable gastric banding; Sleeve 30 gastrectomy; Gastric bypass. 
Recently, bariatric surgery (BS) has been shown to be effective against type 2 diabetes (T2D) in patients with obesity, improving glycemic control, quality of life, and reducing cardiovascular risk, compared to patients not undergoing $\mathrm{BS}^{1,2}$. In recent years a sharp increase in the number of bariatric procedures has been observed worldwide. ${ }^{3}$ The most

55 commonly performed bariatric procedures in France and in other countries are the adjustable gastric band (AGB), sleeve gastrectomy (SG), which are both considered restrictive procedures, and the gastric bypass (GB). There is evidence that BS is effective not only in inducing a significant loss of weight with consequent improvement of T2D but also in the control of microvascular and macrovascular complications linked to T2D. ${ }^{4}$ However, more

60 information is needed on the long-term outcomes of BS on T2D complications. ${ }^{5}$ Interestingly, Courcoulas et al. suggested that new evidence may notably come from the analyses of electronic medical records. ${ }^{6}$ Indeed, a few observational studies have investigated whether BS may prevent the onset of T2D and its related complications in patients with obesity. ${ }^{7,8}$ However, obesity-related metabolic comorbidities work as confusion factors in these studies 65 because not only are they associated with the onset of T2D microvascular and macrovascular complications but potentially they also influence the choice of whether to perform BS or not. Indeed, one of the potential biases is represented by the fact that patients undergoing BS are in better health than control patients who may not be selected to undergo BS because of their poor health status. Therefore, if healthier patients have a greater chance to undergo BS this 70 may account, at least in part, for an association between BS and a reduced rate of T2D complications. To avoid this major bias, patients with microvascular or macrovascular T2D complications should be excluded at baseline to ensure that only patients free of serious comorbidities are included. In a study population where obesity is diagnosed before the diagnosis of T2D and other comorbidities, the choice to undergo BS is not influenced by this 
75 factor. However, the number of subjects would be too high and the time needed to observe T2D and its vascular complications too long for an observational study. The analysis of a large nationwide database with long-term follow-up may allow this issue to be overcome. In this setting, we analyzed data obtained from the French National Health Service for all patients with obesity with at least one-year follow-up who were free of T2D and others

80 vascular comorbidities. The aim of our study was to estimate the preventive effect of BS against T2D and its vascular complications in patients with obesity without comorbidity at baseline.

\section{Materials and Methods}

85 We conducted a national multi-institutional retrospective observational study on patients with

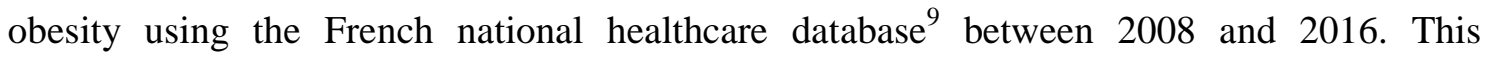
nationwide database collects data of all patients seeking medical advice at emergency facilities as outpatients, admitted as inpatients into all French public and private hospitals, or treated at an outpatient surgical facility. The data includes date of birth, gender, main diagnoses and related diagnoses, information on the annual number of surgical procedures performed in each facility, and provides exhaustive information on all surgical interventions in France. All institutions have been mandated to provide billing data prospectively for each patient. Data are abstracted by medical doctors and certified reviewers. Institutions and facilities are audited annually for accuracy by the national health insurance service, which randomly selects and investigates medical records. Each patient is identified with an anonymous and unique identifier, which allows a linkage of each stay over time and across facilities. Since 2008, financial funds of public and private French facilities depend entirely on data declared through this system. It should be noted that for the same procedure, a hospital stay for a given patient generates a higher fee for the facility if at least one 
comorbidity is coded, which, in turn, leads to a strong tendency toward exhaustive coding. After obtaining approval from the "Commission Nationale Informatique et Liberte" we queried the "Agence Technique de l'Information Hospitalière" to have access to the server of the French national healthcare database for all patients discharged between 2008 and 2016 with diagnosis codes for morbid obesity based on the International Classification of Disease, 10th edition: E66-00 to E66-09, E66-8 to E66-89, and E66-90 to E66-99. Eligible patients were 18 to 60 years old, had at least two different hospital stays between 2008 and 2016, and a minimum delay of one year between the first and the last stay. The age range of 18 to 60 years corresponds to $97.5 \%$ of the age distribution for patients undergoing BS in France and was chosen to avoid an over-representation of older patients in patients with obesity who did not undergo BS. Follow-up began on the discharge date of the first stay. Patients who at baseline or during the first year of follow-up had a history of diabetes, myocardial infarction, congestive heart failure or renal failure were excluded. T2D and its complications were considered to be a new onset when the related diagnostic codes appeared in a new hospital stay after a minimum delay of at least one year after the first hospital stay for morbid obesity.

115 Patients were then divided into two groups: those undergoing BS (BS group) and those who had no history of BS (control group). Each report contains therapeutic procedures, based on the "Classification Commune des Actes Médicaux" (CCAM, 11th edition), which is a national standardized classification of medical procedures. The procedure for extracting the data has been described elsewhere. ${ }^{10}$ In brief, BS procedures were identified with the 120 following CCAM codes: open (HFMA009, HFMA006, HFMA011, HFKA001, HFKA002) and laparoscopic (HFMC007, HFMC005, HFMC008, HFKC001) AGB; open (HFCA001, HGCA009) and laparoscopic (HFCC003, HGCC027) GB; and open (HFMA010) and laparoscopic (HFMC006) SG. To compare outcomes associated with each type of bariatric procedure, patients who underwent revisional or conversional surgeries were excluded. 
125 Outcomes of interest in our study were T2D and its complications, which included foot ulcers, nephropathy, neuropathy, retinopathy, peripheral circulatory and multiple complications (including abscess with T2D, hyperosmolar state or macrovascular complications). The codes retained from the International Classification of Diseases, 10th edition (ICD10) for the main diagnosis or related diagnosis were as follows: E11, E12, E13,

130 E14 corresponding to T2D, E1(1 to 4)-2 corresponding to nephropathy due to T2D, E1-3 corresponding to retinopathy due to T2D, E1-4 corresponding to neuropathy due to T2D, E15 corresponding to peripheral circulatory complications due to T2D, E1-6 corresponding to multiple complications due to T2D and L97 corresponding to foot ulcers. Other data extracted from the French national health care database included age, gender, body mass index (BMI), cardiovascular and metabolic comorbidities (type 1 diabetes, T1D; hypertension, HT; dyslipidemia; vitamin D deficiency; and obstructive sleep apnea syndrome, OSAS), using the ICD10 codes of the algorithm defined by Quan. ${ }^{11}$

\section{Statistical Analyses}

140 Descriptive statistics are used to present demographic and clinical characteristics. Categorical variables are presented as the count and percentage of patients in each category. Univariate comparison analyses were performed using chi-square tests. Continuous variables were summarized using the mean and standard deviation as appropriate. An unpaired $t$ test was used to compare two independent groups and analysis of variance for more than two groups.

145 For event-free survival analysis, we analyzed the data of patients that had been admitted at least once after a hospital stay with a diagnosis of obesity, for any medical reason, i.e. at least two hospital stays between 2008 and 2016 and one year of follow-up. Baseline was defined as the date of the first hospital stay with a diagnosis of obesity and survival time was computed as the difference between this date and the date of a hospital stay with a diagnosis 
of T2D or the date of the last hospital stay for patients without a diagnosis of T2D. KaplanMeier analysis was used to determine the cumulative rates of event-free survival. Log-rank tests were performed to test the difference between the Kaplan-Meier estimation curves obtained on the surgery group and non-surgery group on one hand and the three categories of BS procedures on the other. The proportional hazards assumption was graphically evaluated by a review of log-log survival curves. Covariates, for which the proportional hazard assumption was not satisfied, were included in the Cox model through stratification. Multivariate-adjusted Cox proportional hazards regression models were performed to estimate hazard ratios (HRs) and 95\% confidence intervals, on the outcomes controlling for age, gender, BMI, and baseline differences between surgery and non-surgery groups. To eliminate the selection bias associated with observational studies, a propensity score was calculated corresponding to the likelihood of each individual undergoing BS. Therefore, a logistic regression model was performed including demographic and clinical characteristics at baseline. A quintile propensity score was included in a first Cox model through stratification. Following methods of Parsons ${ }^{12}$, a second Cox model matched on propensity score in a 1:1 manner was then performed. As proposed by Austin ${ }^{13}$, standardized differences were calculated to evaluate the comparability of propensity-matched groups. P values and $95 \%$ confidence intervals are two-sided, a p-value of less than 0.05 was considered significant. All statistical analyses were performed using SAS Enterprise 5.1 (SAS Institute, Cary, NC).

\section{Results}

From 2008 to $2016,374,585$ patients with obesity, aged 18 to 60 years with at least one year of follow-up and free of T2D at baseline and during the first year, were admitted in a French private or public hospital (Figure 1). After excluding patients with major comorbidities, revisional or conversional procedures or a history of T1D, 328,509 patients met inclusion 
175 criteria. From this population, 102,627 (31.2\%) patients did undergo BS and 225,882 (68.8 $\%$ ) did not undergo BS and were considered as control patients. The mean age of the whole study population was 41.9 years $( \pm 11.7)$ and $73 \%$ of patients were women (Table 1$)$. Patients in the BS group were more likely to be younger $(\mathrm{p}<0.001)$ and have a higher BMI at baseline $(\mathrm{p}<0.001)$ than patients in the control group. The latter were more likely to have a history of 180 hypertension and dyslipidemia $(\mathrm{p}<0.001)$ but less likely to have vitamin $\mathrm{D}$ deficiency $(\mathrm{p}<0.001)$. There was no difference between the two groups in the prevalence of OSAS. The mean observation time was 3.6 years in the non-surgery group $(813,175$ person-years) and 3.8 years in the BS group $(389,983$ person-years $)(\mathrm{p}<0.001)$. The mean time interval between the first hospital stay for morbid obesity and a hospital stay that included the diagnosis of T2D was $4.2 \pm 2.0$ years after AGB against $3.8 \pm 2.0$ years after GB and $3.5 \pm 1.9$ years after SG $(\mathrm{p}<0.001)$. The rate of new onset T2D in the control group was $13.2 \%(29,855$ patients out of $225,882)$ and $2.0 \%(2,091$ out of 102,627$)$ in the BS group $(\mathrm{p}<0.001)$. The most common surgical procedure was SG, with 45,698 patients (44.5\%), followed by AGB and then GB, corresponding to $29,616(28.9 \%)$ and 27,313 patients (26.6\%), respectively. In the BS group, the rate of new onset T2D was $4.5 \%(1,348$ out of 29,616$)$ in patients with AGB, $1.2 \%$ (320 out of 27,313) in patients with GB and $0.9 \%(423$ out of 45,698) in patients with SG ( $p<0.001$ AGB vs GB; $p<0.001$ AGB vs SG). The rate of multiple complications due to T2D was $1 \%(2,222$ out of 225,882 patients) in the control group and $0.1 \%$ (107 out of 102,627 patients) in the BS group ( $<<0.001)$. The same difference was found between patients in the 195 control group and those in the BS group for all T2D complications, namely peripheral circulatory complications, foot ulcer, neuropathy, nephropathy, and retinopathy (Table 1). Interestingly, patients who had AGB were more likely to present with peripheral circulatory complications, neuropathy, nephropathy, and retinopathy when compared to those who underwent GB and SG (Table 1). The analysis of survival curves showed that BS was 
associated with favorable 8-year T2D event-free survival estimates, corresponding to $92.3 \%$ for patients with obesity who underwent BS compared to $58.2 \%$ for patients with obesity who did not undergo BS (Figure 2A). Estimates differed significantly (Log-rank test: $\mathrm{p}<0.001)$ between the procedures, 8 -year unadjusted event-free survival estimates were $86.8 \%$ after AGB, against $95.5 \%$ and $95.8 \%$ after GB and SG, respectively $(\mathrm{p}<0.001)$ (Figure 2B). In multivariate analysis, BS was associated with a significantly reduced risk of developing T2D and its complications after adjusting for baseline differences (Table 2). The adjusted HR for a diagnosis of T2D and for T2D multiple complications in the BS group versus the control group was $\mathrm{HR}=0.18$ (95\% CI 0.17 to 0.19$)$ and $\mathrm{HR}=0.14$ (95\% CI 0.12 to 0.18$)$, respectively. A similar result was found for each of the T2D complications (Table 2). A propensity-score model was applied to our study, including 30 predictor variables, leading to a well calibrated (Hosmer-Lemeshow goodness of fit test $\mathrm{p}=0.92)$ and discriminant model $(\mathrm{C}$ statistic $=0.80)$. Patient characteristics of a 1:1 propensity-matched sample and standardized difference are presented in Table 3. There were 94,595 subjects in each arm, mean age and sex ratio were the same in the BS group and control group, i.e. the mean age was 38 years and $85 \%$ of each group were female. Both stratification on the propensity score and matching resulted in similar estimates. The reduction in the risk of T2D and its complications confirmed estimates obtained in multivariate analysis (Table 4).

\section{Discussion}

220 This study shows that patients who underwent BS had an $82 \%$ lower risk of developing T2D compared to patients with obesity who had no history of BS. This result has been confirmed on 328,509 patients with obesity free of diabetes (T2D) at baseline with at least one year of follow-up. Although several studies have already shown the effect of BS on T2D remission ${ }^{14-}$ ${ }^{17}$, very few have compared the new onset of $\mathrm{T} 2 \mathrm{D}$ in patients with obesity who have 
undergone BS with a non-surgical population of patients with obesity. Results observed in our study are coherent with the 12-year incidence of T2D presented by Adams et al. ${ }^{2}$ in an observational, prospective study of patients with obesity who underwent GB and two nonsurgery groups of patients with obesity who did not undergo BS. In the study by Adams et al., only 3\% (8 of 303) of patients with a 12-year follow-up after GB developed T2D against $26 \%$ (89 of 348) in the non-surgery group. In the present study, between 2008 and 2016 only $2 \%$ of patients developed T2D after BS $(2,091$ of 102,627$)$ against $13 \%$ of patients in the control group $(29,855$ of 225,882$)$. Although the rate of T2D was found to be higher in the study by Adams et al. than in our data, the fact that the national database only captured hospital stays may account for the difference, by not including all the patients for whom a diagnosis of T2D was made, for example, in primary care and not requiring a hospital stay. The longer follow-up in the study by Adams et al. may also account for the higher rate of T2D in both groups. However, as all patients included in the present study had at least two hospital stays and one year of follow-up the chance of missing the diagnosis of T2D was the same in both groups. Carlsonn et al. ${ }^{7}$ followed-up 1,658 patients who had BS and 1,771 obese matched controls, aged 37 to 60 years old and free of T2D at baseline, for 15 years. In this study, the risk reduction of developing T2D was $83 \%$ in the BS group compared to the non-surgery group. We observed a risk reduction of $82 \%$ in our population study, which corresponds to a reduction twice as large as that observed with lifestyle interventions in obese subjects. ${ }^{18,19}$ With a population study of 102,627 primary BS procedures, corresponding to $24544.5 \%$ SG, $28.9 \% \mathrm{AGB}$, and $26.6 \% \mathrm{~GB}$, the present study has the power to compare results obtained by each procedure. Indeed, we were able to show that the new onset of T2D was significantly greater in patients after AGB than those who underwent GB or SG, $4.5 \%$ against $1.2 \%$ and $0.9 \%$, respectively. Although it is well known that both SG and GB are more effective against T2D compared to $\mathrm{AGB}^{20-22}$, the comparative effect of $\mathrm{SG}$ and $\mathrm{GB}$ on $\mathrm{T} 2 \mathrm{D}$ is 
250 still debated. ${ }^{23,24}$ As with other studies on T2D remission ${ }^{25-27}$, our data indicate that SG and GB have a similar effect on T2D prevention. As recently pointed out by O'Brien et al. ${ }^{28}$, few studies have included a non-surgical population to compare microvascular outcomes after $\mathrm{BS}^{1,28,29}$ and even less with patients with euglycemia or prediabetes at the baseline. ${ }^{30}$ Carlsonn et al. found that BS was associated with a reduced risk of microvascular 255 complications, especially in patients with prediabetes ${ }^{30}$, with a hazard reduction of $82 \%$. Johnson et al. ${ }^{8}$ also reported an adjusted hazard reduction of $78 \%$ in the surgical group compared to the non-surgical group. In our study, the hazard reduction for microvascular complications due to T2D is coherent with these data, from an $89 \%$ lower risk of presenting with a nephropathy due to T2D to a $78 \%$ lower risk of foot ulcers, in patients who had BS 260 compared to the control group. Our study has some limitations. Firstly, this is a retrospective, observational study based on electronic administrative data extracted from 2008 to 2016, and we cannot ensure that the two groups of patients were strictly comparable at baseline. In other words, it may be speculated that patients in the control group avoided BS because of an increased operative risk linked to poorer general health, thus generating a selection bias.

265 However, by selecting patients aged 18 to 60 years of age, representing $97.5 \%$ of patients undergoing BS between 2008 and 2016, without serious comorbidity at the time of the first hospital stay with a diagnosis of obesity, we aimed to select patients with obesity in the two groups that were comparable with respect to the potential choice of undergoing BS. In fact, patients with obesity undergoing BS were younger than those who did not (37 vs 44 years of 270 age, $\mathrm{p}<0.001$ ), suggesting that the former were less likely to develop $\mathrm{T} 2 \mathrm{D}$ and its complications. However, at the baseline, $40 \%$ of patients in the BS had a BMI in the range 40 to 50 against $15 \%$ of patients of the control group. Moreover, our multivariate analysis adjusted for age and BMI confirmed the results obtained in the univariate analysis. Furthermore, we applied a propensity score model to limit the selection bias, which enabled 
275 us to compare two groups of 95,000 patients with obesity, matched one on one with exactly the same age, i.e. 38 years old. The analysis of this propensity-matched population also found an $81 \%$ reduction in the risk of developing T2D after BS. The same estimate was found with a second Cox model stratified on propensity score quintiles for all the study population. Underreporting the diagnosis of T2D may also be claimed as a limitation. However, it should

280 be noted that when this diagnosis is mentioned it doubles the fee that the French health insurance system have paid since 2008. Another major limitation of the present study is represented by the missing information on the body weight of patients after BS. Consequently, it was not possible to identify patients in whom BS had failed. This information would have allowed us to investigate whether the high rate of new onset T2D in the group of patients who underwent AGB compared to GB and SG is linked to a difference in the loss of weight. However, it should also be considered that other mechanisms are involved in GB and SG that may account for a more effective antimetabolic efficacy. Furthermore, the PMSI database does not capture information issued from primary care and this may contribute to underestimate the incidence of T2D in both groups. Finally, there were too few T2D complications to draw strong conclusions. To increase the number of cases with T2D complications we could have included patients with T2D at the baseline. However, this would have added a major selection bias on the comparability of groups. Furthermore, as there were no biological measures available in the French National Health database, we would have not been able to adjust outcomes on the glycemic level before BS. Indeed, if 295 patients with a better glycemic control were selected for BS, a misleading association with less complicating events could have been observed compared to the control groups. This is why we preferred to limit the analysis to patients free of T2D at baseline and for the first year. To conclude, the results from this nationwide large and long-term observational study 
demonstrate that $\mathrm{BS}$ is effective in preventing $\mathrm{T} 2 \mathrm{D}$ and its complications in patients with 300 obesity when compared to patients who have not undergone BS.

305 Conflict of Interest The authors of this manuscript declare no conflicts of interest with any commercial labels or pharmaceutical industries. 


\section{References}

1. Schauer PR, Bhatt DL, Kirwan JP, et al. Bariatric Surgery versus Intensive Medical Therapy for Diabetes - 5-Year Outcomes. N Engl J Med. 2017;376:641 $\square 51$.

2. Adams TD, Davidson LE, Litwin SE, et al. Weight and Metabolic Outcomes 12 Years after Gastric Bypass. N Engl J Med. 2017;377:1143 $\square 55$.

3. Angrisani L, Santonicola A, Iovino P, et al. Bariatric Surgery Worldwide 2013. Obes Surg. 2015;25:1822 $\square 32$.

340

4. Sjöström L, Peltonen M, Jacobson P, et al. Association of bariatric surgery with longterm remission of type 2 diabetes and with microvascular and macrovascular complications. JAMA. 2014;311:2297 $\square 304$.

345 5. Adams TD, Arterburn DE, Nathan DM, et al. Clinical Outcomes of Metabolic Surgery: Microvascular and Macrovascular Complications. Diabetes Care. 2016;39:912 $\square 23$. 
6. Courcoulas AP, Yanovski SZ, Bonds D, et al. Long-term outcomes of bariatric surgery: a National Institutes of Health symposium. JAMA Surg. 2014;149:1323 $\square 9$.

7. Carlsson LMS, Peltonen M, Ahlin S, et al. Bariatric surgery and prevention of type 2 diabetes in Swedish obese subjects. N Engl J Med. 2012;367:695 $\square 704$.

8. Johnson BL, Blackhurst DW, Latham BB, et al. Bariatric surgery is associated with a reduction in major macrovascular and microvascular complications in moderately to severely obese patients with type 2 diabetes mellitus. J Am Coll Surg. 2013;216:545 $\square 56$.

9. Bailly L, Schiavo L, Sebastianelli L, et al. Anemia and Bariatric Surgery: Results of a National French Survey on Administrative Data of 306,298 Consecutive Patients Between 2008 and 2016. Obes Surg. 2018;28:2313 $\square 20$.

10. Lazzati A, Audureau E, Hemery F, et al. Reduction in early mortality outcomes after bariatric surgery in France between 2007 and 2012: A nationwide study of 133,000 obese patients. Surgery. 2016;159:467 $\square 74$.

11. Quan H, Sundararajan V, Halfon P, et al. Coding algorithms for defining comorbidities in ICD-9-CM and ICD-10 administrative data. Med Care. 2005;43:1130 $\square 9$. 
12. Parsons LS. Performing a $1: \mathrm{N}$ case-control match on propensity score. [Internet]. SAS Institute, Cary, NC.; 2004. Disponible on: Proceedings of the Twenty-ninth Annual SAS Users Group International (SUGI) Conference, 2004.

375

13. Austin PC. Balance diagnostics for comparing the distribution of baseline covariates between treatment groups in propensity-score matched samples. Stat Med. $2009 ; 28: 3083 \square 107$.

14. Buchwald H, Estok R, Fahrbach K, et al. Weight and type 2 diabetes after bariatric surgery: systematic review and meta-analysis. Am J Med. 2009;122:248-256.

15. Arterburn DE, Bogart A, Sherwood NE, et al. A multisite study of long-term remission and relapse of type 2 diabetes mellitus following gastric bypass. Obes Surg. $2013 ; 23: 93 \square 102$.

16. Aminian A, Brethauer SA, Andalib A, et al. Can Sleeve Gastrectomy «Cure» Diabetes? Long-term Metabolic Effects of Sleeve Gastrectomy in Patients with Type 2 Diabetes. Ann Surg. 2016;264:674 $\square 81$.

17. Purnell JQ, Selzer F, Wahed AS, et al. Type 2 Diabetes Remission Rates After Laparoscopic Gastric Bypass and Gastric Banding: Results of the Longitudinal Assessment of Bariatric Surgery Study. Diabetes Care. 2016;39:1101 $\square 7$. 
18. Lindström J, Peltonen M, Eriksson JG, et al. Improved lifestyle and decreased diabetes risk over 13 years: long-term follow-up of the randomised Finnish Diabetes Prevention Study (DPS). Diabetologia. 2013;56:284 $\square 93$.

19. Haw JS, Galaviz KI, Straus AN, et al. Long-term Sustainability of Diabetes Prevention Approaches: A Systematic Review and Meta-analysis of Randomized Clinical Trials. JAMA Intern Med. 2017;177:1808 $\square 17$.

20. Wang S, Li P, Sun XF, et al. Comparison between laparoscopic sleeve gastrectomy and laparoscopic adjustable gastric banding for morbid obesity: a meta-analysis. Obes

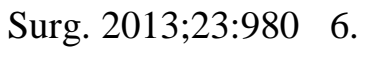

21. Abbatini F, Rizzello M, Casella G, et al. Long-term effects of laparoscopic sleeve gastrectomy, gastric bypass, and adjustable gastric banding on type 2 diabetes. Surg Endosc. 2010;24:1005 $\square 10$.

410

22. Himpens J, Dapri G, Cadière GB. A prospective randomized study between laparoscopic gastric banding and laparoscopic isolated sleeve gastrectomy: results after 1 and 3 years. Obes Surg. 2006;16:1450 $\square$.

415 23. Lee W-J, Chong K, Ser K-H, et al. Gastric Bypass vs Sleeve Gastrectomy for Type 2 Diabetes Mellitus: A Randomized Controlled Trial. Arch Surg. 2011;146:143 $\square 8$. 
24. Knop FK. Resolution of type 2 diabetes following gastric bypass surgery: involvement of gut-derived glucagon and glucagonotropic signalling? Diabetologia. 2009;52:2270 6 .

25. Cho J-M, Kim HJ, Lo Menzo E, et al. Effect of sleeve gastrectomy on type 2 diabetes as an alternative treatment modality to Roux-en-Y gastric bypass: systemic review and meta-analysis. Surg Obes Relat Dis. 2015;11:1273 $\square 80$.

425

26. Jiménez A, Casamitjana R, Flores L, et al. Long-term effects of sleeve gastrectomy and Roux-en-Y gastric bypass surgery on type 2 diabetes mellitus in morbidly obese subjects. Ann Surg. 2012;256:1023 $\square 9$.

27. Shoar S, Saber AA. Long-term and midterm outcomes of laparoscopic sleeve gastrectomy versus Roux-en-Y gastric bypass: a systematic review and meta-analysis of comparative studies. Surg Obes Relat Dis. 2017;13:170 $\square 80$.

28. O’Brien R, Johnson E, Haneuse S, et al. Microvascular Outcomes in Patients with Diabetes After Bariatric Surgery Versus Usual Care: A Matched Cohort Study. Ann Intern Med. 2018;169:300-10.

29. Carlsson LMS, Romeo S, Jacobson $P$, et al. The incidence of albuminuria after bariatric surgery and usual care in Swedish Obese Subjects (SOS): a prospective controlled intervention trial. Int J Obes. 2005. 2015;39:169 $\square 75$. 
30. Carlsson LMS, Sjöholm K, Karlsson C, et al. Long-term incidence of microvascular disease after bariatric surgery or usual care in obesity patients, stratified by baseline glycaemic status: a post-hoc analysis of participants from the Swedish Obese Subjects study. Lancet Diabetes Endocrinol. 2017;5:271 $\square 9$.

450

\section{Figure legends}

Figure 1. Flow chart of patient's selection.

455 Figure 2. Unadjusted T2D-free survival estimates for morbidly obese inpatients with and without bariatric surgery. 
Figure 1

\section{Study population}

Morbidly obese patients aged 18 to 60 years old without history of T2D and at least one year of follow-up $\mathrm{N}=\mathbf{3 7 4 , 5 8 5}$

Excluded for T1D N=13,100

Excluded for major comorbidity $*=23,879$

Excluded for revisional/conversional BS=9,097

Morbidly obese patients included in study $\mathrm{N}=328,509$

Free of T2D or complications the first year of follow-up

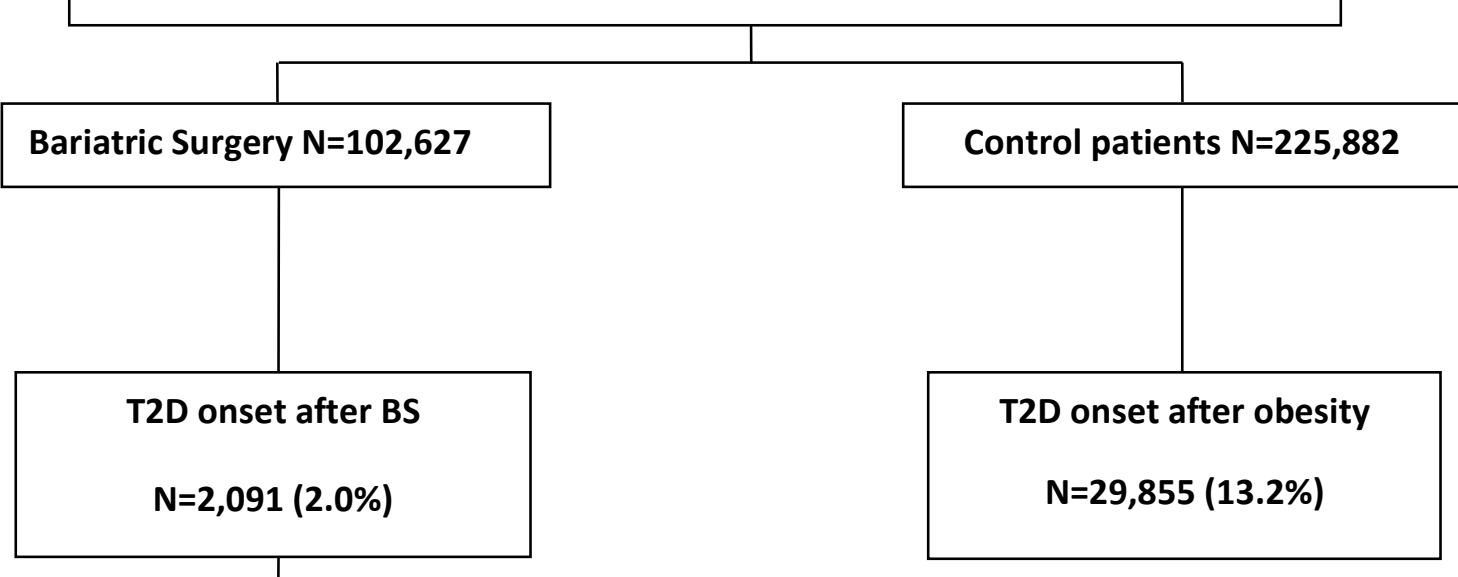

Primary AGB $(\mathrm{N}=29,616)$

T2D onset $\mathrm{N}=1,348(4.5 \%)$

Abbreviations: $B S=$ Bariatric Surgery, $T 2 D=T y p e ~ 2$ Diabetes, T1D=Type 1 Diabetes, AGB=Adjustable Gastric Banding, $\mathrm{GB}=$ Gastric Bypass, $\mathrm{SG}=$ Sleeve Gastrectomy.

*Myocardial infarction, congestive heart failure, chronic renal failure 


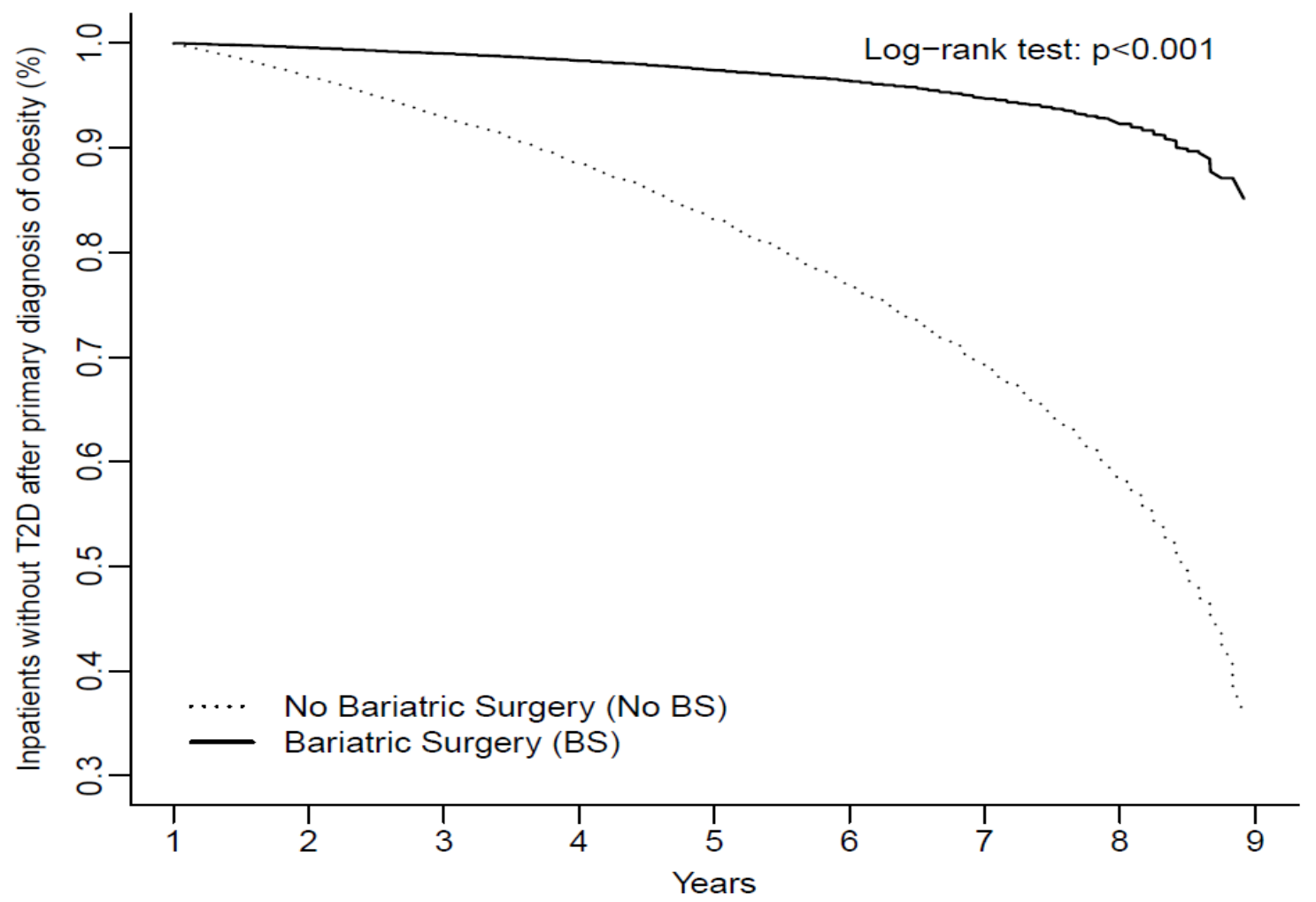

\begin{tabular}{|rccccccccc|}
\hline BS $(n):$ & 102627 & 79407 & 59410 & 43192 & 28551 & 17411 & 8654 & 2825 & 44 \\
No BS $(n):$ & 225882 & 168683 & 124122 & 87909 & 56560 & 33295 & 16142 & 5136 & 99 \\
\hline
\end{tabular}

Number at risk

A

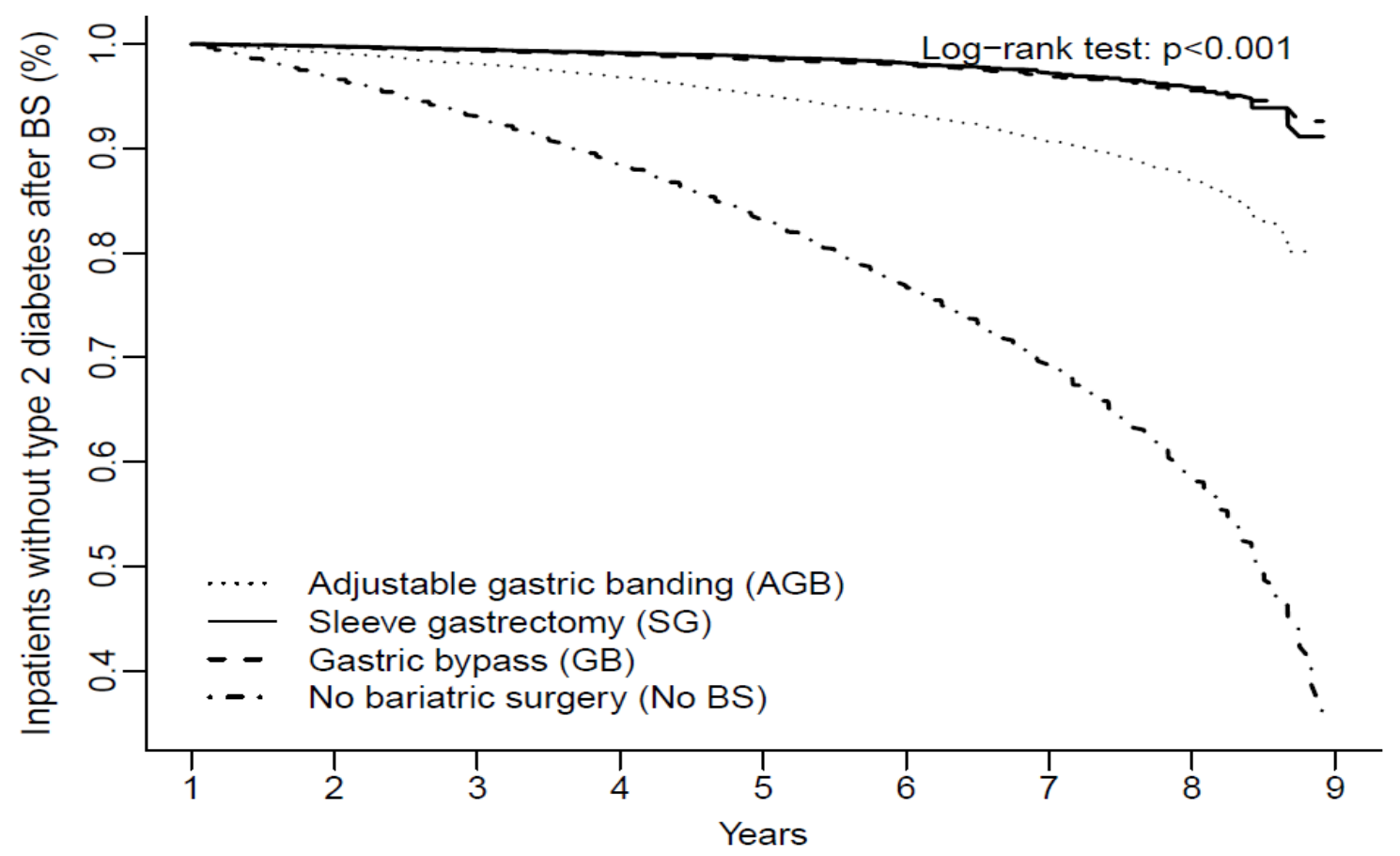

\begin{tabular}{|cccccccccc|}
\hline AGB (n): & 29616 & 24669 & 19861 & 15211 & 10417 & 6617 & 3420 & 1154 & 21 \\
SG (n): & 45698 & 33641 & 23971 & 16819 & 10722 & 6274 & 2941 & 922 & 11 \\
GB (n): & 27313 & 21097 & 15578 & 11162 & 7412 & 4520 & 2293 & 749 & 12 \\
No BS (n): & 225882 & 168683 & 124122 & 87909 & 56560 & 33295 & 16142 & 5136 & 99 \\
\hline
\end{tabular}

Number at risk 
Table 1. Characteristics of studied 328,509 morbidly obese inpatients at baseline and outcomes of interest, France $2008-2016$

\begin{tabular}{|c|c|c|c|c|c|c|c|c|}
\hline Characteristic & $\begin{array}{c}\text { Population } \\
\text { study* }(328,509)\end{array}$ & $\begin{array}{c}\text { Control patients } \\
(225,882)\end{array}$ & $\begin{array}{c}\text { Bariatric surgery } \\
(102,627)\end{array}$ & $\mathbf{p}$ & $\begin{array}{c}\text { AGB } \\
(29,616)\end{array}$ & $\begin{array}{c}\text { Gastric bypass } \\
(27,313)\end{array}$ & $\begin{array}{c}\text { Sleeve gastrectomy } \\
(45,698)\end{array}$ & $\mathbf{p}$ \\
\hline \multicolumn{9}{|c|}{ At baseline } \\
\hline Mean age \pm SD & $41.9 \pm 11.7$ & $44.0 \pm 11.7$ & $37.3 \pm 10.5$ & $<0.001$ & $37.2 \pm 10.5$ & $38.0 \pm 10.3$ & $37.1 \pm 10.5$ & $<0.001$ \\
\hline Sex ratio, $M / F, \%$ & $27.0 / 73.0$ & $32.9 / 67.1$ & $13.8 / 86.2$ & $<0.001$ & 11.0/89.0 & $13.0 / 87.0$ & $16.0 / 84.0$ & $<0.001$ \\
\hline Hypertension, \% & 20.8 & 24.4 & 12.8 & $<0.001$ & 11.4 & 14.0 & 13.1 & $<0.001$ \\
\hline Dyslipidemia, \% & 8.4 & 10.0 & 4.9 & $<0.001$ & 4.0 & 5.5 & 5.3 & $<0.001$ \\
\hline OSAS, $\%$ & 9.2 & 9.3 & 9.1 & 0.05 & 5.6 & 11.2 & 10.1 & $<0.001$ \\
\hline itamin D deficiency, \% & 1.9 & 1.5 & 2.8 & $<0.001$ & 1.1 & 3.1 & 3.6 & $<0.001$ \\
\hline $\mathrm{BMI}<40, \%$ & 52.6 & 59.7 & 37.0 & $<0.001$ & 38.8 & 31.8 & 39.0 & $<0.001$ \\
\hline BMI 40-50, \% & 23.0 & 15.0 & 40.6 & $<0.001$ & 39.0 & 45.9 & 38.4 & $<0.001$ \\
\hline BMI $>50, \%$ & 3.0 & 1.8 & 5.7 & $<0.001$ & 3.2 & 6.8 & 6.7 & $<0.001$ \\
\hline
\end{tabular}

\begin{tabular}{|c|c|c|c|c|c|c|c|c|}
\hline \multicolumn{9}{|c|}{ Outcomes of interest } \\
\hline Type 2 Diabetes, n (\%) & $31,946(9.7)$ & $29,855(13.2)$ & $2,091(2.0)$ & $<0.001$ & $1,348(4.5)$ & $320(1.2)$ & $423(0.9)$ & $<0.001$ \\
\hline $\begin{array}{c}\text { Mean time of follow-up in } \\
\text { years } \pm \text { SD }\end{array}$ & $3.70 \pm 1.96$ & $3.65 \pm 1.95$ & $3.81 \pm 1.98$ & $<0.001$ & $4.23 \pm 2.03$ & $3.77 \pm 1.98$ & $3.55 \pm 1.91$ & $<0.001$ \\
\hline Multiple complications & $2,329(0.7)$ & $2,222(1.0)$ & $107(0.1)$ & $<0.001$ & $66(0.2)$ & $18(0.1)$ & $23(0.1)$ & $<0.001$ \\
\hline $\begin{array}{l}\text { Peripheral circulatory } \\
\text { complications, } n(\%)\end{array}$ & $2,280(0.7)$ & $2,205(1.0)$ & $75(0.1)$ & $<0.001$ & $45(0.1)$ & $9(0.0)$ & $22(0.0)$ & $<0.001$ \\
\hline Foot ulcer, n (\%) & $1,964(0.6)$ & $1,823(0.8)$ & $141(0.1)$ & $<0.001$ & $45(0.1)$ & $32(0.1)$ & $64(0.1)$ & 0.52 \\
\hline Neuropathy, n (\%) & $1,790(0.5)$ & $1,723(0.8)$ & $67(0.1)$ & $<0.001$ & $34(0.1)$ & $8(0.0)$ & $25(0.0)$ & $<0.001$ \\
\hline Nephropathy, n (\%) & $1,933(0.6)$ & $1,857(0.8)$ & $76(0.1)$ & $<0.001$ & $55(0.2)$ & $9(0.0)$ & $12(0.0)$ & $<0.001$ \\
\hline Retinopathy, n (\%) & $682(0.2)$ & $637(0.3)$ & $45(0.0)$ & $<0.001$ & $29(0.1)$ & $6(0.0)$ & $10(0.0)$ & $<0.001$ \\
\hline
\end{tabular}

* without revisional, conversional procedure or comorbidity, free of type 1 or type 2 diabetes and with at least one year of follow-up.

AGB: Adjustable Gastric Band, BMI: Body Mass Index, SD: Standard Deviation, M/F: Males/Females, OSAS: Obstructive Sleep Apnea Syndrome 
Table 2. Adjusted hazard ratios for type 2 diabetes and complications due to T2D in bariatric surgery vs non-surgery patients

\begin{tabular}{|c|c|c|c|c|c|c|c|}
\hline & $\begin{array}{c}\text { Type } 2 \text { Diabetes } \\
\text { HR }_{\mathbf{a}}(95 \% \mathrm{CI}) \\
(\mathbf{N}=31,946)\end{array}$ & $\begin{array}{c}\text { Multiple } \\
\text { complications } \\
(\mathrm{N}=2,329)\end{array}$ & $\begin{array}{c}\text { Peripheral } \\
\text { circulatory } \\
\text { complications } \\
(\mathrm{N}=\mathbf{2 , 2 8 0})\end{array}$ & $\begin{array}{c}\text { Foot ulcer } \\
(\mathrm{N}=1,964)\end{array}$ & $\begin{array}{l}\text { Nephropathy } \\
(\mathbf{N}=\mathbf{1 , 9 3 3 )}\end{array}$ & $\begin{array}{l}\text { Neuropathy } \\
(N=1,790)\end{array}$ & $\begin{array}{l}\text { Retinopathy } \\
\quad(\mathrm{N}=682)\end{array}$ \\
\hline Non-surgery & 1.0 (Referent) & 1.0 & 1.0 & 1.0 & 1.0 & 1.0 & 1.0 \\
\hline Bariatric surgery & $0.18(0.17-0.19)$ & $0.14(0.12-0.18)$ & $0.16(0.13-0.21)$ & $0.22(0.18-0.26)$ & $0.11(0.09-0.14)$ & $0.12(0.09-0.15)$ & $0.21(0.16-0.29)$ \\
\hline Female & 1.0 (Referent) & 1.0 & 1.0 & 1.0 & 1.0 & 1.0 & 1.0 \\
\hline Male & $1.29(1.26-1.32)$ & $1.44(1.32-1.57)$ & $2.27(2.08-2.48)$ & $2.18(1.99-2.39)$ & $1.70(1.55-1.87)$ & $1.50(1.37-1.66)$ & $1.08(0.92-1.26)$ \\
\hline Age 18 to 29 & 1.0 (Referent) & 1.0 & 1.0 & 1.0 & 1.0 & 1.0 & 1.0 \\
\hline Age 30 to 39 & $1.67(1.57-1.77)$ & $1.49(1.17-1.90)$ & $3.20(1.96-5.25)$ & $1.72(1.29-2.29)$ & $0.96(0.76-1.20)$ & $1.70(1.25-2.31)$ & $1.46(0.93-2.30)$ \\
\hline Age 40 to 49 & $2.18(2.06-2.30)$ & $1.76(1.41-2.21)$ & $5.55(3.46-8.93)$ & $2.67(2.04-3.48)$ & $1.11(0.89-1.37)$ & $2.44(1.83-3.27)$ & $1.94(1.27-2.97)$ \\
\hline Age 50 to 60 & $2.26(2.14-2.39)$ & $1.78(1.42-2.23)$ & $7.29(4.55-11.69)$ & $4.42(3.41-5.74)$ & $0.89(0.72-1.10)$ & $2.26(1.69-3.01)$ & $2.18(1.44-3.32)$ \\
\hline Hypertension & $1.83(1.79-1.88)$ & $2.74(2.44-3.07)$ & $3.38(2.96-3.86)$ & $1.80(1.61-2.00)$ & $3.04(2.67-3.46)$ & $2.69(2.36-3.07)$ & $2.59(2.10-3.19)$ \\
\hline Dyslipidemia & $1.70(1.66-1.74)$ & $2.45(2.25-2.68)$ & $2.99(2.73-3.28)$ & $0.88(0.80-0.98)$ & $2.94(2.66-3.24)$ & $2.44(2.21-2.70)$ & $2.49(2.12-2.93)$ \\
\hline BMI 30-40 & 1.0 (Referent) & 1.0 & 1.0 & 1.0 & 1.0 & 1.0 & 1.0 \\
\hline BMI 40-50 & $1.32(1.28-1.36)$ & $1.43(1.28-1.61)$ & $1.13(1.00-1.27)$ & $2.12(1.88-2.39)$ & $1.42(1.26-1.61)$ & $1.33(1.17-1.52)$ & $1.29(1.04-1.60)$ \\
\hline $\mathrm{BMI}>50$ & $1.78(1.66-1.91)$ & $1.60(1.20-2.13)$ & $1.47(1.07-2.01)$ & $6.72(5.59-8.09)$ & $1.83(1.36-2.46)$ & $1.63(1.17-2.26)$ & $1.51(0.88-2.60)$ \\
\hline
\end{tabular}

$\mathrm{HR}_{\mathrm{a}}(95 \% \mathrm{CI})$ : Adjusted Hazard Ratio (95\% Confidence Interval), BMI: Body Mass Index 
Table 3. Comparability of propensity-matched groups: bariatric surgery versus control patients

\begin{tabular}{cccc}
\hline Characteristic & $\begin{array}{c}\text { Bariatric } \\
\text { surgery }\end{array}$ & $\begin{array}{c}\text { Control } \\
\text { patients }\end{array}$ & $\begin{array}{c}\text { Standardized } \\
\text { difference \% }\end{array}$ \\
\hline n & $\mathbf{9 4 , 5 9 5}$ & $\mathbf{9 4 , 5 9 5}$ & \\
\hline Mean age $\mathbf{4 S D}$ & $38.0 \pm 10.4$ & $38.0 \pm 11.1$ & 0.3 \\
Sex ratio, M/F, \% & $14.6 / 85.4$ & $14.6 / 85.4$ & 0.1 \\
Hypertension, \% & 27.0 & 28.2 & -2.6 \\
Dyslipidemia, \% & 12.3 & 13.7 & -4.3 \\
OSAS, \% & 25.3 & 26.9 & -3.7 \\
Vitamin D deficiency, \% & 13.4 & 11.0 & 7.3 \\
BMI <40, \% & 38.3 & 49.5 & \\
BMI 40-50, \% & 39.4 & 26.3 & 19.8 \\
BMI >50, \% & 5.3 & 3.1 & \\
BMI NS, \% & 17.0 & 21.1 &
\end{tabular}

BMI: Body Mass Index, SD: Standard Deviation, M/F: Males/Females, OSAS: Obstructive Sleep Apnea Syndrome 
Table 4 Hazard ratios for type 2 diabetes and complications due to T2D in bariatric surgery vs non-surgery patients (Referent) and in propensity stratified and matched sample

\begin{tabular}{|c|c|c|c|c|c|c|c|}
\hline & $\begin{array}{c}\text { Type } 2 \text { Diabetes } \\
\text { HR } 95 \% \text { CI }\end{array}$ & $\begin{array}{c}\text { Multiple } \\
\text { complications }\end{array}$ & $\begin{array}{l}\text { Peripheral } \\
\text { circulatory } \\
\text { complications }\end{array}$ & Foot ulcer & Nephropathy & Neuropathy & Retinopathy \\
\hline Unadjusted HR & $\mathbf{0 . 1 4}(0.13-0.15)$ & $\mathbf{0 . 1 0}(0.08-0.12)$ & $\mathbf{0 . 0 7}(0.06-0.09)$ & $\mathbf{0 . 1 7}(0.14-0.20)$ & $\mathbf{0 . 0 9}(0.07-0.11)$ & $\mathbf{0 . 0 8}(0.06-0.11)$ & $\mathbf{0 . 1 5}(0.11-0.21)$ \\
\hline Adjusted* HR & $\mathbf{0 . 1 8}(0.17-0.19)$ & $\mathbf{0 . 1 4}(0.12-0.18)$ & $\mathbf{0 . 1 6}(0.13-0.21)$ & $0.22(0.18-0.26)$ & $\mathbf{0 . 1 1}(0.09-0.14)$ & $\mathbf{0 . 1 2}(0.09-0.15)$ & $\mathbf{0 . 2 1}(0.16-0.29)$ \\
\hline Propensity stratified HR & $\mathbf{0 . 1 7}(0.17-0.18)$ & $\mathbf{0 . 1 5}(0.12-0.18)$ & $\mathbf{0 . 1 6}(0.13-0.20)$ & $\mathbf{0 . 2 3}(0.19-0.28)$ & $\mathbf{0 . 1 3}(0.10-0.16)$ & $\mathbf{0 . 1 1}(0.09-0.15)$ & $\mathbf{0 . 2 2}(0.16-0.30)$ \\
\hline 1:1 Propensity matched HR & $\mathbf{0 . 1 8}(0.17-0.19)$ & $\mathbf{0 . 1 1}(0.06-0.19)$ & $\mathbf{0 . 1 1}(0.06-0.21)$ & $\mathbf{0 . 5 8}(0.46-0.72)$ & $\mathbf{0 . 0 9}(0.05-0.15)$ & $\mathbf{0 . 2 3}(0.15-0.34)$ & $\mathbf{0 . 1 7}(0.09-0.33)$ \\
\hline
\end{tabular}

HR: Hazard ratio, 95\%CI: Confidence Limits 95\%, *Ajusted on age, gender, BMI and baseline differences 